\title{
Clinical Reasoning: A 49-year-old man with progressive numbness, weakness, and evidence of leptomeningeal enhancement
}

Alexandra Lovett, MD, Kathleen McKee, MD, and Sashank Prasad, MD

Neurology ${ }^{\circledast}$ 2018;90:e90-93. doi:10.1212/WNL.0000000000004770

\section{Section 1}

A 49-year-old man with a medical history significant for diabetes mellitus, a left thigh sarcoma that was resected 5 years prior, and a seizure disorder on valproic acid presented with 2 months of progressive numbness and weakness. Symptoms began with painful paresthesias in both thumbs that progressed to numbness. His feet subsequently became numb, and within 3 weeks he noted gait unsteadiness. During this time he also experienced a 25-pound weight loss. He subsequently developed intermittent diplopia, worst on downgaze. He denied recent sick contacts, prior exposure to tuberculosis, or tick bites. He was admitted to an outside hospital and subsequently transferred to our facility for further care.

The patient's examination on arrival was remarkable for a left partial third nerve palsy, a left lower motor neuron facial droop, and wasting of the bilateral interossei and thenar/hypothenar eminences. He had weakness of left-sided finger abduction, adduction, and flexion, $2 / 5$ strength in dorsiflexion bilaterally, and $4 / 5$ strength in plantarflexion bilaterally. Sensation was decreased to all modalities in a stocking-glove distribution. Reflexes were symmetric but diminished distally. Rapid hand movements were uncoordinated.

\section{Questions for consideration:}

1. How would you localize this patient's symptoms and presenting examination?

2. What is your differential diagnosis at this time?

3. What additional workup would you recommend?
Correspondence

Dr. Lovett

ajlovett@partners.org

\section{GO TO SECTION 2}

From the Department of Neurology (A.L., K.M.), Massachusetts General Hospital; and Department of Neurology (A.L., K.M., S.P.), Brigham and Women's Hospital, Boston, MA. Go to Neurology.org/N for full disclosures. Funding information and disclosures deemed relevant by the authors, if any, are provided at the end of the article. 


\section{Section 2}

The distal nature of the sensory and motor symptoms along with hyporeflexia localizes to the peripheral nervous system. A brain or spinal cord lesion is much less likely. Third nerve palsy can sometimes occur with midbrain lesions, but in the context of the other findings is probably a peripheral lesion. The facial nerve palsy with involvement of the forehead localizes to the 7 th nerve as it exits the brainstem or along its peripheral course. The most unifying localization of this patient's symptoms is a process involving multiple peripheral nerves. Peripheral cranial nerve involvement also raises the possibility of brainstem leptomeningeal involvement.

The differential diagnosis includes indolent infection such as Lyme meningitis with polyradiculitis or less likely fungal, viral, or tubercular meningitis; an inflammatory process such as neurosarcoidosis; demyelinating polyneuropathy; paraneoplastic neuropathy; and leptomeningeal carcinomatosis. Motor neuron disease is unlikely given the presence of sensory symptoms. Vasculitis is unlikely in the absence of pain.

Lumbar puncture revealed a pleocytosis of 123 white blood cells $/ \mathrm{mL}$ with a $95 \%$ lymphocytic predominance, protein of $474 \mathrm{mg} / \mathrm{dL}$, and glucose of $103 \mathrm{mg} / \mathrm{dL}$. MRI of the brain and cervical, thoracic, and lumbar spine with IV gadolinium contrast confirmed leptomeningeal enhancement of multiple bilateral cranial nerves, the conus, and the cauda equina (figure 1).CT scans of the chest, abdomen, and pelvis revealed a $2 \mathrm{~cm}$ renal mass. MRI evaluation of the left thigh ruled out recurrence of the sarcoma. There were no FDG-avid lesions on PET scan.

Cytology and flow cytometry preformed on CSF from 2 additional large volume taps as well as CSF immunoglobulin $\mathrm{H}$ gene rearrangement were all negative for malignant cells. CSF $\beta 2$ microglobulin was elevated and oligoclonal bands were present. Serum protein electrophoresis revealed a double gammopathy with immunoglobulin $G$ lambda paraproteins and $2 \mathrm{M}$-spikes with a background of polyclonal immunoglobulins. Serum fungal studies, T-spot tuberculosis test, HIV antibodies, treponemal antibody, Lyme, and inflammatory markers (including antinuclear antibody, antineutrophil cytoplasmic antibody, anti-Ro/La antibodies, rheumatoid factor, and myelin associated glycoprotein antibodies) were all negative. HIV viral load was not checked. Angiotensin converting enzyme level was normal. Serum erythrocyte sedimentation rate was $67 \mathrm{~mm} / \mathrm{h}$. CSF fungal studies, Lyme, venereal disease research laboratory test, herpes simplex virus PCR, and cytomegalovirus PCR were negative. An EMG and nerve conduction study demonstrated the following findings: an unobtainable right median-D2 sensory nerve action potential (SNAP); a decreased amplitude right ulnar-D5 SNAP with prolonged peak latency and reduced conduction velocity; absent compound muscle action potential (CMAP) in the right median abductor pollicis brevis (APB), left peroneal extensor digitorum brevis, and bilateral tibial abductor hallucis; and severely reduced amplitude and markedly prolonged distal latency of the right median-lumbrical, right ulnar-interosseous, left medial-APB, and left ulnar-abductor digiti minimi CMAP. F-waves were not tested. These results provided electrodiagnostic evidence for a demyelinating polyneuropathy.

Because the diagnosis remained uncertain on clinical grounds and metastatic carcinoma remained a possibility, a lumbosacral nerve root biopsy was obtained. Histopathology showed a polyclonal T-lymphocytic inflammatory infiltrate and early demyelination with macrophage infiltration (figure 2).

\section{Question for consideration:}

1. What is the final diagnosis?

Figure $1 \mathrm{MRI}$ brain and lumbosacral spine
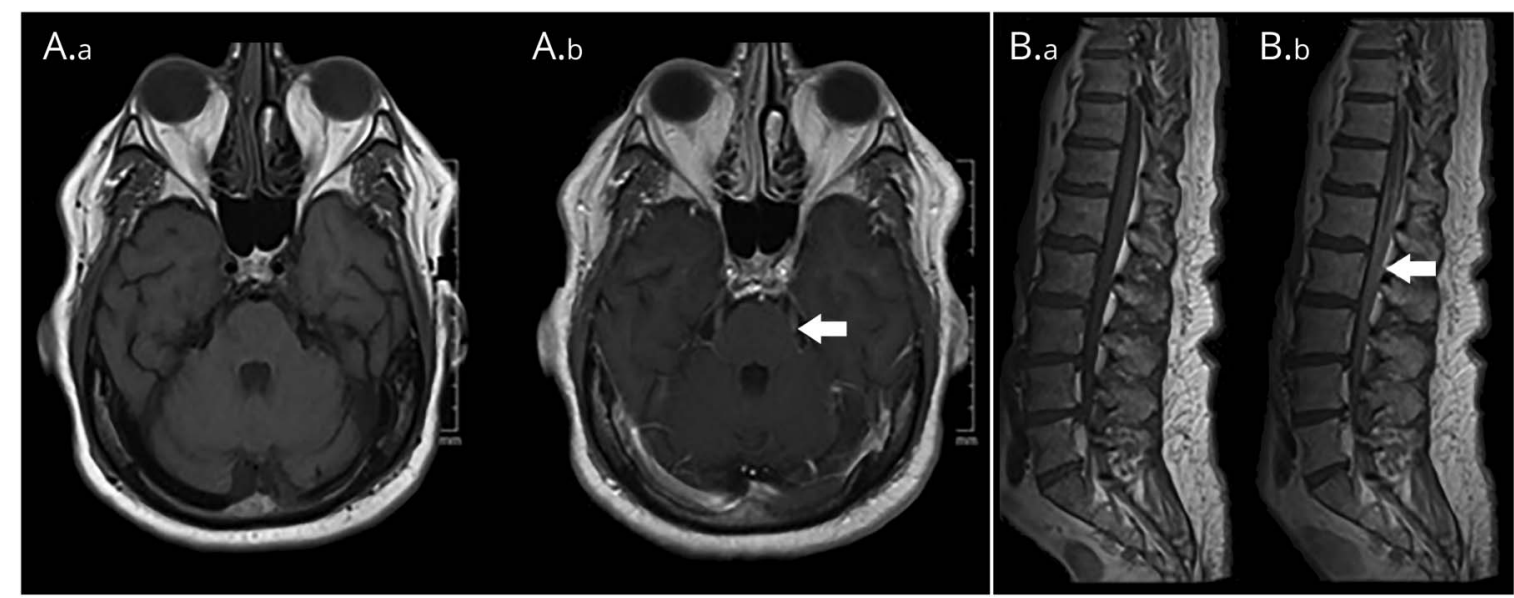

(A) MRI brain and (B) MRI lumbosacral spine T1 sequences with (A.a, B.a) precontrast images and (A.b, B.b) postcontrast images. Leptomeningeal enhancement is visible along bilateral trigeminal nerves on axial brain cuts (arrow) and in cauda equina on sagittal lumbosacral spine (arrow). 
Figure 2 Histopathology slide demonstrates lumbar nerve root with lymphocytic infiltrate

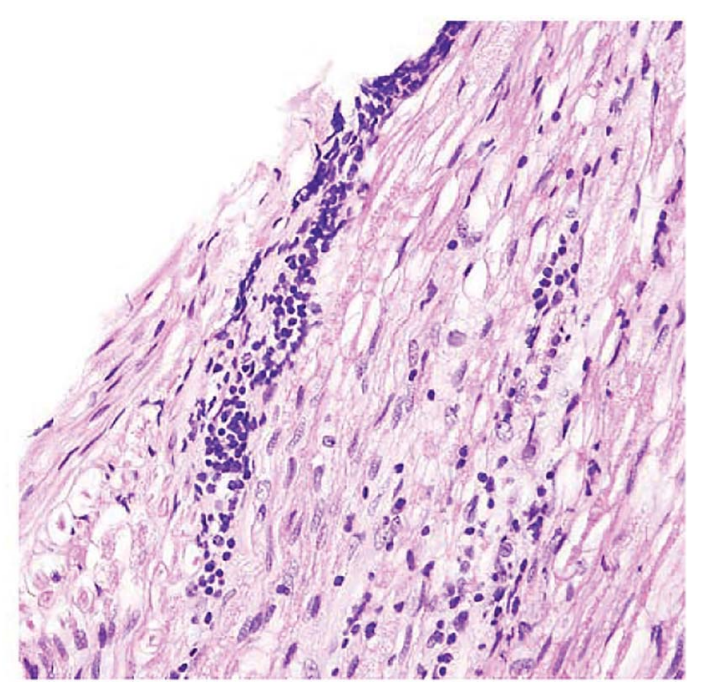

Magnification $\times 20$.

GO TO SECTION 3 


\section{Section 3}

The patient was diagnosed with chronic inflammatory demyelinating polyradiculoneuropathy (CIDP) based on clinical presentation, presence of oligoclonal bands in the CSF, EMG findings, and nerve biopsy. His examination worsened over the initial days of his hospitalization with development of a right third nerve palsy and near-complete paralysis of the lower extremities (hip flexion remained 1/5). He was treated with 7 days of IV methylprednisolone and 5 days of IV immunoglobulin (IVIg). His neurologic examination improved and he was discharged to rehabilitation on a steroid taper.

The patient was followed clinically over the next 8 months with scheduled IVIg infusions at 5-week intervals. He experienced further improvement in his symptoms. His diplopia resolved though he continued to have anisocoria from his left $3 \mathrm{rd}$ nerve palsy. His left 7 th nerve palsy improved with minimal residual deficits. The strength in his upper and lower extremities improved proximally more than distally, to the point that he was able to kick his legs and stand with assistance. After biopsy, the renal mass was determined to be a low-grade malignancy and is being monitored with regular clinical surveillance.

\section{Discussion}

The CSF pleocytosis and prominent bulbar findings with cranial nerve enhancement observed in this patient are atypical for CIDP. Classically CIDP entails fairly symmetric weakness involving proximal and distal muscles lasting more than 8 weeks ${ }^{1}$ with a CSF albuminocytologic dissociation and rare cranial nerve involvement. CIDP is an autoimmune disease mediated pathophysiologically by $\mathrm{T}$ cells and macrophages with macrophage-mediated myelin stripping. ${ }^{1,2}$ Pathology demonstrates onion bulbs in $10 \%-40 \%$ of nerve biopsies in patients with CIDP, as well as foci of endoneurial or perivascular inflammation with macrophage clusters around endoneurial vessels, demyelination, and axonal degeneration. ${ }^{1,3}$ Nerve biopsy has limited diagnostic utility in typical CIDP but, as in this case, can be useful to exclude mimics. ${ }^{1} \mathrm{CIDP}$ is also thought to be mediated by a humoral component based on evidence that immunoglobulins from patients with CIDP can be transfused to animal models and induce demyelination. ${ }^{1}$

The patient fulfilled European Federation of Neurological Societies/Peripheral Nerve Society (EFNS/PNS) clinical and electrodiagnostic criteria for a diagnosis of definite CIDP, with supportive studies including nerve root enhancement on MRI, nerve biopsy, and clinical improvement after immunomodulatory therapy. The lymphocytic pleocytosis in this case was atypical. ${ }^{4}$ CSF in CIDP typically demonstrates an albuminocytologic dissociation. Lymphocytic pleocytosis in patients with symptomatology of CIDP should raise suspicion for coinfection or an additional disease process including but not limited to HIV,
Lyme disease, monoclonal gammopathy of undetermined significance, sarcoidosis, or lymphoma. ${ }^{1,2,4}$ Evaluation for these conditions in this patient was negative. In addition, his clinical improvement on IVIg alone is inconsistent with an infectious or malignant process. Lumbar puncture was repeated approximately 5 months after initial presentation and found only 1 leukocyte $/ \mathrm{mL}$ in tube 4 . Cranial nerve involvement was another atypical feature of this case; however, case reports have documented cranial nerve hypertrophy manifesting with ophthalmoplegia in patients with CIDP, ${ }^{3}$ and the inclusionary criteria under the EFNS/PNS guidelines stipulate cranial nerves may be affected in CIDP. ${ }^{4}$

Establishing a diagnosis of CIDP is important because of its excellent response to immunomodulatory agents. This case was unusual because the initial lymphocytic pleocytosis in the CSF necessitated an expanded workup to exclude other disease processes. Other considerations for further workup in atypical cases can include hematologic evaluation, skeletal survey, and bone marrow biopsy. ${ }^{1}$ First-line treatment of CIDP is with corticosteroids, plasma exchange, or IVIg. ${ }^{1}$ Patients treated with IVIg should be treated at a dose of $2 \mathrm{~g} / \mathrm{kg}$ at induction and then maintenance dosing at $0.4-1 \mathrm{~g} / \mathrm{kg}$ every 3-4 weeks thereafter with a goal of eventually tapering off treatment. ${ }^{1}$ Prognostically, patients with CIDP do well with marked improvement on immunosuppressive therapy, though there is approximately a $50 \%$ relapse rate. ${ }^{1}$ Better outcomes have been reported in patients with less than 1 year of symptoms and an acute exacerbation at the time of IVIg therapy. Progressive course and CNS involvement portend a higher degree of disability. ${ }^{1}$

\section{Author contributions}

Alexandra Lovett: case report writeup, literature search, author. Kathleen McKee: coauthor. Sashank Prasad: coauthor.

\section{Study funding}

No targeted funding reported.

\section{Disclosure}

The authors report no disclosures relevant to the manuscript. Go to Neurology.org/ $\mathrm{N}$ for full disclosures.

\section{References}

1. Dimachkie MM, Barohn RJ. Chronic inflammatory demyelinating polyneuropathy. Curr Treat Options Neurol 2013;15:350-366.

2. Peltier AC, Donofrio PD. Chronic inflammatory demyelinating polyradiculoneuropathy: from bench to bedside. Semin Neurol 2012;32:187-195.

3. Alwan AA, Mejico LJ. Ophthalmoplegia, proptosis, and lid retraction caused by cranial nerve hypertrophy in chronic inflammatory demyelinating polyradiculoneuropathy. J Neuro-ophthalmol 2007;27:99-103.

4. Hughes RAC, Bouche P, Cornblath DR, et al. European Federation of Neurological Societies/Peripheral Nerve Society guideline on management of chronic inflammatory demyelinating polyradiculoneuropathy: report of a joint task force of the European Federation of Neurological Societies and the Peripheral Nerve Society. Eur J Neurol 2006; 13:326-332. 


\title{
Neurology
}

\author{
Clinical Reasoning: A 49-year-old man with progressive numbness, weakness, and \\ evidence of leptomeningeal enhancement \\ Alexandra Lovett, Kathleen McKee and Sashank Prasad \\ Neurology 2018;90;e90-e93 \\ DOI 10.1212/WNL.0000000000004770
}

This information is current as of December 28, 2017

Updated Information \&

Services

References

Subspecialty Collections

Permissions \& Licensing

Reprints including high resolution figures, can be found at: http://n.neurology.org/content/90/1/e90.full

This article cites 4 articles, 0 of which you can access for free at: http://n.neurology.org/content/90/1/e90.full\#ref-list-1

This article, along with others on similar topics, appears in the following collection(s):

Chronic inflammatory demyelinating polyneuropathy

http://n.neurology.org/cgi/collection/chronic_inflammatory_demyelinat ing_polyneuropathy

EMG

http://n.neurology.org/cgi/collection/emg

Information about reproducing this article in parts (figures,tables) or in its entirety can be found online at:

http://www.neurology.org/about/about_the_journal\#permissions

Information about ordering reprints can be found online:

http://n.neurology.org/subscribers/advertise

Neurology ${ }^{\circledR}$ is the official journal of the American Academy of Neurology. Published continuously since

1951, it is now a weekly with 48 issues per year. Copyright Copyright @ 2017 American Academy of

Neurology. All rights reserved. Print ISSN: 0028-3878. Online ISSN: 1526-632X.

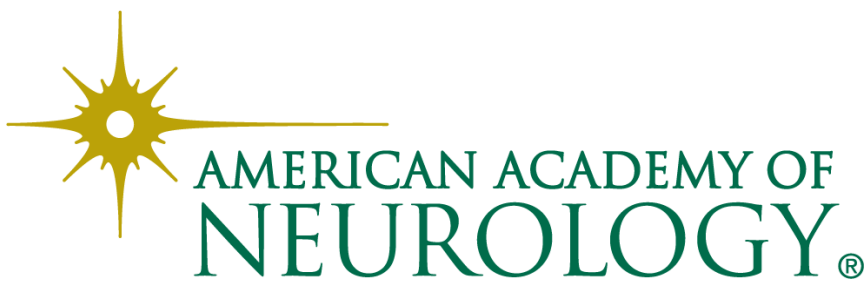

